\title{
Three-dimensionally fused gadolinium-enhanced and diffusion-weighted images: value in determination of multi-centricity of breast carcinoma
}

\author{
H Sherif, A Mahfouz, A Kambal, A Sayedin*, I Mujeeb \\ From International Cancer Imaging Society (ICIS) 14th Annual Teaching Course \\ Heidelberg, Germany. 9-11 October 2014
}

\section{Purpose}

72 patients with biopsy-proven breast carcinoma were sent to MR imaging for preoperative assessment of multicentricity. Based on mastectomy/lumpectomy specimens and further biopsies, 47 patients had single lesions, and 25 had multiple lesions with a total number of 116 proven malignant foci. The preoperative MR images were retrospectively reviewed and post-processed to obtain three-dimensional fused images of early gadolinium enhancement (encoded in red) and diffusionweighted images (encoded in green) at $b=1500 \mathrm{~s} / \mathrm{mm}^{2}$. To eliminate the T2 shine-through effect, lesions with $\mathrm{ADC} \geq$ $1 \times 10^{-3} \mathrm{~mm}^{2} / \mathrm{s}$ were eliminated. The post-processed images were reviewed by an experienced blinded radiologist, who noted all the lesions with a diameter $\geq 5 \mathrm{~mm}$, classifying them into three groups: matched enhancement and diffusion restriction (matched E-DR), unmatched diffusion restriction (DR), and unmatched enhancement (E).

\section{Results}

313 lesions with a diameter $\geq 5 \mathrm{~mm}$ were identified. 101 lesions showed matched E-DR. Taking matched E-DR as indicative of malignancy, sensitivity, specificity, positive predictive value, negative predictive value and accuracy for diagnosis of individual malignant foci were $84.5,98.5,97$, 91, and $93.3 \%$ respectively. Three false positive foci of matched E-DR were due to fibroadenomas. 18 false negative foci have been due to foci of DCIS less than $1 \mathrm{~cm}$ in diameter. Conclusion: Fused images of gadolinium enhancement and diffusion restriction offer a reasonably

\footnotetext{
* Correspondence: Asayedin0@gmail.com
} Hamad Medical Corporation, Doha, Qatar

Submit your next manuscript to BioMed Central and take full advantage of:

- Convenient online submission

- Thorough peer review

- No space constraints or color figure charges

- Immediate publication on acceptance

- Inclusion in PubMed, CAS, Scopus and Google Scholar

- Research which is freely available for redistribution 